\title{
Effect of Education Nursing Program on Preventive Practices of Urinary Tract Infection among Community-Dwelling Older Adults
}

\author{
Basma Taher Abd-Elwahab Mohamed, Assistant Lecturer \\ Gerontological Nursing, Faculty of Nursing, Damanhour University \\ Hanaa Shafik Ibrahim, Professor \\ Gerontological Nursing, Faculty of Nursing, Alexandria University \\ Zaghloul Elsafy Ibrahim Gouda, Consultant Nephrologist \\ Deputy Chair of Research and Training, Damanhour Medical National Institute \\ Hanaa Abou El-soued Hussein Ahmed, Assistant Professor
Gerontological Nursing, Faculty of Nursing, Alexandria University
}

Abstract

Urinary tract infection (UTI) is a life-threatening and fatal problem for community-dwelling older adults, and its prevalence in both sexes increases with age. UTI has a significant impact on the overall health of older adults. It can lead to increased morbidity and mortality, as well as impose a societal economic burden. Gerontological nurses are the key responsible for applying education nursing programs in order to promote preventive measures, provide patient education, and evaluate evidence-based practice (EBP) approaches to reduce UTI in community-dwelling older adults. Objective: Determine the effect of education nursing program on preventive practices of urinary tract infection among community-dwelling older adults. Setting: Damanhour National Medical Institute in El Behera Governorate, Egypt, in two outpatient clinics namely; urology clinic and internal medicine clinic. Subjects: A convenience sample of 50 community-dwelling older adults who did not have UTI. Tools: Five tools were used for data collection: I. Mini-Mental State Examination (MMSE), II. Urinary Tract Infection Symptoms Assessment (UTISA), III. Community-dwelling Older Adults' Sociodemographic and Clinical Data Structured Interview Schedule, IV. Community-dwelling Older Adults' Knowledge about Preventive practices of UTI Assessment Sheet, and V. Community-dwelling Older Adults' UTI Preventive practices Checklist. Results: There were significant improvements in the study subjects' knowledge and practice levels in all areas of knowledge and practice about UTI after the implementation of the study intervention and the differences were statistically significant. The proposed education nursing program had a highly significant effect on the study subjects' UTI preventive practices (0.96) for knowledge and (0.91) for practice. Conclusion: The proposed education nursing program had a highly significant effect on preventive practices regarding UTI and observed statistically significant differences between the prior to and immediately after the program. This improvement has been regretted over time (six weeks post-program), but is still better than before. Recommendations: A written UTI preventive practice guidelines should be developed by an interdisciplinary team comprised of physicians, gerontological nurses, and other health care providers for managing UTI in outpatient clinics for older adults. These guidelines should be reviewed and updated on a regular basis.

Keywords: Education nursing program; Urinary tract infection; Preventive practices Communitydwelling older adults.

\section{Introduction}

Although the fact that urinary tract infection (UTI) is a preventable and curable health problem, it is still the most common infectious disease in older adults. It was recognized as the second infection after respiratory tract infection among older adults (Nicolle, 2018). UTI is a broad term for an infection of the urinary system that can affect either the lower urinary tract or upper urinary tract or both (Jump et al., 2018). 
In older adults, the presence of urinary tract-specific symptoms and significant bacteriuria with a quantitative count of $>10^{5}$ colony-forming units of bacteria per milliliter $(\mathrm{CFU} / \mathrm{ml})$ in one urine specimen is usually required for the diagnosis of UTI. Asymptomatic bacteriuria (ASB) is described as the presence of bacteria in the urine in the absence of clinical signs or symptoms suggestive of a urinary tract infection (UTI) (Goldman \& Julian, 2019). In the USA, UTI causes an estimated 7 million office visits, 1 million emergency room visits, and 100,000 hospitalizations in older adults each year, and more than $15 \%$ of patients who develop gram-negative bacteremia die each year, accounting for $25 \%$ of all infections (Mody \& JuthaniMehta, 2014).

The prevalence of UTI among older adults varies widely between nations; in the United States (USA), women over 65 years are diagnosed with UTI at a rate of $45 \%$ to $55 \%$, while men of the same age are diagnosed at a rate of $33 \%$ to $46 \%$ (Crnich et al., 2017). Furthermore, in Alexandria, Egypt, $75 \%$ to $85 \%$ of geriatric patients hospitalized at the Main University Hospital and Health Insurance Hospital had UTI respectively, while in El Behera, Egypt, the percent of older adults admitted to Damanhur National Medical Institute outpatient clinics and suffering from UTI was $65 \%$ to $75 \%$ (Hospital Statistical Records, 2015, 2019).

Older adults have numerous risk factors for developing UTI. Aging is the first and most important one. For example, with age, the smooth muscle and elastic tissue of the bladder are replaced with fibrous tissues, resulting in decreased bladder capacity and muscle tone. Decreased bladder capacity leads to incomplete bladder emptying and increased post-void residual urine. Furthermore, urinary tract infection is more common in elderly women due to hormonal changes such as fluctuation and insufficiency in the circulating level of estrogen, which cause thinning and increased fragility of the urethral mucosa. Reduced glycogen content in vaginal epithelial cells; decreased acidic PH of urine also leads to increased bacterial colonization, resulting in an increased risk of UTI (Vasudevan, 2014, Knight et al., 2019). Additionally, alterations in the male urinary system include a decrease in the antibacterial action of prostate secretion, which leads to an increase in bacterial colonization in the urethra and an increase in susceptibility to UTI (Coker, \& Dierfeldt, 2016).

In addition to age-related changes, UTI is more common in older adults who have diabetes, dehydration, limited mobility, or urinary incontinence (Homma et al., 2011; Midthuns, 2015). Furthermore, any obstructive urinary tract condition, such as a tumor, kidney stones, or benign prostatic hyperplasia $(\mathrm{BPH})$, may raise the risk of UTI among them. Additionally, the presence of a urinary catheter, Cerebral-Vascular Accident (CVA), and cognitive impairment all contribute to an increased risk of UTI (Coker \& Dierfeldt, 2016). All of these risk factors would increase hospitalization, treatment failure, and mortality in older adults (Goldman \& Julian, 2019; Griebling, 2020).

UTI in older adults can be manifested by a variety of typical symptoms, such as nausea, vomiting, stomach discomfort, urinary frequency, urgency, suprabupic pain, or tenderness. Women may feel discomfort or pressure above the pubic bone, while men may sense fullness in the rectum (Nicolle, 2018). Community-dwelling older adults who have bacteremic UTI often do not have typical manifestations of UTI because agerelated changes in the immune system reduce the body's response to infection (Bigel et al., 2019). They may exhibit atypical manifestations, such as low grade fever, confusion, lethargy, dyspnea, cough, and anorexia, as well as a sudden episode of urinary incontinence, foul-smelling urine, and a general sense of being ill (Elbeddini, 2018). Because of the lack of typical 
symptoms of UTI and the decreased host defense mechanism, diagnosis, prevention, and treatment are often difficult in older adults (Crnich, 2017).

A complicated UTI can vary from asymptomatic bacteriuria to gram-negative sepsis with shock. UTI is the second most common cause of septicemia in people over 65 years old, with a mortality rate of more than $60 \%$ (Abelson et al., 2018). UTI is a serious health disease that has a significant impact on the general health and well-being of older adults (Woodford \&George, 2011). Untreated UTI can progress to a potentially fatal and life-threatening condition known as chronic kidney infection, as well as permanent kidney damage as a result of persistent upper UTI (Matthews, 2011; Alpay et al., 2018). Consequently, it reduced older adults' quality of life, as well as caused an increase in the cost of health-care services and caregiver stress. Hence, early detection and treatment of UTI are crucial for lowering morbidity and mortality in older adults (Goldman \& Julian, 2019).

Health care providers should differentiate between asymptomatic baceriurea and symptomatic UTI. Although antimicrobials are effective in the treatment of symptomatic UTI in older adults, they are not recommended for the treatment of asymptomatic baceriurea due to the probability of antimicrobial resistance and Adverse Drug Reactions (Griebling, 2020, Kranz et al., 2018, Khanal, 2020).

In this regard, non-pharmacological approaches, such as the proposed education nursing program, are a critical component in the prevention of UTI in communitydwelling older adults. According to reports, it has been shown to be the most efficient in preventing UTI in older adults (Bliemel et al., 2018; Jump et al., 2018). The proposed education nursing program is a comprehensive package of preventive practices aimed at addressing a wide range of needs in older people in order to increase physical and functional capacity, boost immunity, and improve the quality of life (Garretto et al., 2020).

This package is delivered in a set of sessions, focuses on a thorough assessment of older adults, followed by individualized preventive strategies such as basic UTI information regarding its meaning, signs \& symptoms, especially atypical manifestations, and treatment. Additionally, dietary requirements, enough hydration, hygiene care practices, as well as proper exercises such as Kegel's exercise, bladder training, and walking are recommended. Furthermore, medical follow-up and referral services are available (Crnich, 2017; Nicolle, 2018; Rarrick et al., 2020). The proposed education nursing program was designed to provide community-dowelling older adults with the essential information and skills related to appropriate preventive practices (Center for Disease Control and Prevention (CDC), 2021). The proposed program also aids gerontological nurses who work in outpatient clinics in implementing such UTI preventative measures in order to reduce recurrent infection, morbidity and mortality risk, and the overall cost of the therapeutic regimen (Gaurav, 2019; Shallcross et al., 2020).

In this respect, gerontological nurses have greater responsibility and play an important role in older adults' assessment in order to early identify those at risk for UTI and prevent negative consequences. They are also responsible for monitoring the patient's compliance and responsiveness to prescribed management modalities (Laura, 2020). Furthermore, gerontological nurses should evaluate the effectiveness of the proposed education nursing program, taking into account physiological and psychological changes that may interfere with the teaching process, and attempting to overcome such barriers (Flores-Mireles et al., 2015).

\section{Aim of the Study}

The aim of the study is to determine the effect of education nursing program on 
preventive practices of urinary tract infection among community-dwelling older adults.

\section{Research Hypothesis}

Community-dwelling older adults who attend the proposed education nursing program achieve higher post-test scores on UTI preventive practices than before.

\section{Materials and Method}

\section{Materials}

Design: The study followed a quasiexperimental research design, (one group pretest- posttest).

Setting: The study was carried out in the outpatient clinics at Damanhour National Medical Institute in El Behera Governorate, Egypt, which is affiliated to the Ministry of Health and Population. The outpatient clinics include seven clinics. The data was gathered from urology and internal medicine clinics. These clinics were chosen after reviewing the Hospital Statistical Records for the year 2019, which revealed that these clinics had a greater attendance rate of community-dwelling older adults.

Subjects: The study subjects were selected using a convenience sample technique and included fifty (50) community-dwelling older adults who attended the previously mentioned settings and fulfilled the following criteria:

- Aged 60 years and more.

- Had intact cognitive function score (2430) or mild cognitive impairment score (18-23) on Mini-Mental State Examination (MMSE) (Folestein, 1975).

- Free from urinary tract infection (UTI). This was confirmed by:

a- Urine analysis result (Clean Catch Mid-Stream Urine Analysis) reveals absence of pyuria and bacteriuria.

b- Urinary Tract Infection Symptoms Assessment (UTI Symptoms Assessment Tool) reveals no signs and symptoms of UTI.
The Epi info program V 7.0 was used to estimate the sample size using the following parameters: expected frequency: $50 \%$, acceptable error: $3 \%$, confidence coefficient: $97 \%$, the minimum sample size was 49.

Tools: In order to fulfill the objective of the study, five tools were used:

\section{Tool I: Mini-Mental State Examination (MMSE)}

The MMSE was developed by (Folestein et al., 1975), which was translated into Arabic by (Elokl, 2002) and found to be valid and reliable $(\mathrm{r}=0.93)$. It has 20 questions covered the following items about: memory, orientation, registration, attention, calculation, and recall, language, naming, and coping. The overall MMSE score is 30 points, and it is categorized as follows: Normal cognitive function (24-30), Mild cognitive impairment (18-23), and Severe cognitive impairment (0-17).

\section{Tool II: Urinary Tract Infection} Symptoms Assessment (UTISA)

This tool was developed by (Clyson et al., 2004). UTISA is a 7-item selfadministered questionnaire that examines the presence and severity of the seven most frequently reported signs and symptoms of UTI, such as:

- Urinary frequency and urgency.

- Pain/burning on urination, pain in the pelvic area, and low back pain.

- Blood in urine.

- Incomplete voiding.

The presence of symptoms is given a value of one (1), while the absence of symptoms is given a score of zero $(0)$. The total score is assigned a value between 0 and 7 and is classified based on the severity of symptoms as follows: Mild UTI (1-2), Moderate UTI (3-5), and Severe UTI (6-7).

Tool III: Community-dwelling Older Adults' Socio-demographic and Clinical Data Structured Interview Schedule 
It was designed by the researcher based on a review of the relevant literature and covered four parts:

Part 1: Socio-demographic data, such as age, sex, marital status, level of education, place of residence, occupation before retirement, and their monthly income.

Part 2: Clinical data which includes the following items:

- The previous history of UTI.

- Previous hospitalization due to UTI.

- Previous urological surgeries.

- Other medical disorders

- Medications consumed.

Part 3: Physical status of communitydwelling older adults includes the following items:

- Level of mobility (walks unaided, walks with assistance) and the use of assisting devices such as canes, walkers, wheel chairs and/or others.

- Vision (presence of visual defect or impairment).

- Hearing (presence of hearing defect or impairment).

Part 4: Clean Catch Mid-Stream Urine Analysis includes urine characteristics such as color, reaction, quantity, aspect, specific gravity, and microscopic examination such as the presence of pus cells, red blood cells, bacteriuria, and nitrate. The results denote UTI include:

- The presence of bacteriurea.

- The presence of pus cells (above 5 pus cells/H.P.F)

- Turbid urine (absence of urine clarity or cloudy urine) according to the laboratory hospital's standardized normal value.

Tool IV: Community-dwelling Older Adults' Knowledge about Preventive Practices of UTI Assessment Sheet

This tool was designed by the researcher through the review of related literature in order to assess older individuals' knowledge regarding UTI prevention. It contained information on the meaning of UTI, high risk groups, contributing factors, forms of UTI, clinical manifestations of UTI, including atypical signs and symptoms, preventive measures (taking healthy and balanced diet, drinking adequate fluid intake, doing exercises, performing hygienic care practices, and following medical checkup), and negative effects of UTI.

Each correct answer assigned a score of two (2), a correct but incomplete response assigned a score of one (1), and a wrong answer or don't know assigned a score of zero (0). The overall score of the knowledge of community-dwelling older adults ranges from 0 to 14 and is classified as follows:

- Poor knowledge $=0-<7(<50 \%)$.

- Fair knowledge $=7-10(50$ to $<70 \%)$.

- Good knowledge $=11-14$ (70 to100\%).

Tool V: Community-dwelling Older $\begin{array}{lll}\text { Adults' UTI Preventive practices } & \text { U }\end{array}$ Checklist

This tool was developed by the researcher after reviewing related literature to assess older adults' practices of UTI prevention. It included preventive practices such as healthy diet, adequate hydration, and hygienic care practices such as proper perineal hygiene technique and urinary catheter care if present, appropriate types of exercise and their frequency, as well as medical follow-up and referral services, and factors that impede the performance of these practices.

The score of practices was decided as follows: if older adults perform the practice, a score of one (1) was assigned, and if older adults do not perform the practice, a score of zero (0) was assigned. The overall score for preventive practice among communitydwelling older adults ranges from 0 to 10 . The total practice percentage is determined as follows:

- Poor practice $=0-<5(<50 \%)$.

- Good practice $=5$ - $10(\geq 50 \%)$.

\section{Method}

- Before conducting the study, an approval from The Research Ethics Committee (REC) (REC) of the 
Faculty of Nursing, Alexandria University was obtained.

- Permission to carry out the study was obtained from the responsible authorities in the Faculty of Nursing, Alexandria University.

- The Ministry of Health and Population issued an official letter, which was forwarded to the Head of the study setting. The Head of the outpatient clinics was interviewed individually to obtain her permission to collect the data after being informed about the purpose of the study, the date and time of the data collection.

- The study was executed through three (3) main phases:

\section{Preparation phase:}

\section{- Preparation of the study tools:}

- The Arabic version of the tool I Mini-Mental State Examination was used in this study to select the study subjects.

- Tool II Urinary tract Infection Symptoms Assessment was translated into the Arabic language by the researcher and tested for content validity by five (5) experts in related fields of the study namely; Gerontological Nursing, Medical and Surgical Nursing, and Obstetrics \& Gynecological Nursing. The required modifications were carried out accordingly. The Cronbach alpha test was used to assess the tool's reliability on ten (10) communitydwelling older individuals, and the result was $r=0.90$.

- Tool III, tool IV and tool V were developed by the researcher through the review of related literature, and tested for content validity.

\section{- A pilot study:}

- After the development of the study tools, a pilot study was carried out on five (5) community-dwelling older adults. They were selected from the study settings (internal medicine and urology clinics) and they were not enrolled in the study. The appropriate modifications were made as a result.

- Preparation of the proposed education nursing program:

- After reviewing the most recent related literature, the proposed nursing education program was developed by the researcher. This program consisted of five (5) sessions according to the main objectives of the proposed program:

- Session I: introduction and basic information about UTI.

- Session II: dietary requirements and fluid intake necessary for prevention of UTI.

- Session III: hygiene care practices and care of urinary catheter if present.

- Session IV: proper exercises necessary for prevention of UTI.

- Session V: services available for follow-up and referral.

- A brochure entails colorful, illustrative pictures, and the main important points covered in each session were developed by the researcher. The brochure was clear, large 
in size, simple to attract attention, and it accommodates visual impairments in older adults, illustrates the program's content, and simplifies its implementation for UTI prevention.

\section{Implementation phase:}

- The researcher motivates the older adults to attend clinics and engage in the study by assessing their weight, blood pressure, and offering juice, which aids in the development of rapport with the older adults and their families.

- The researcher obtained each study subject's phone number in order to make plans for upcoming meetings; if older persons were unable to attend for follow-up, the researcher visited them at their own homes.

- The researcher conducted a survey of all older adults who attended the clinics to select the study subjects by:

- Assess cognitive function using tool I.

- Assess symptoms of UTI using tool II.

- Assess urine analysis results using Clean Catch Mid-Stream Urine Analysis.

- The researcher interviewed each community-dwelling older adult who met the inclusion criteria individually in the waiting area of the outpatient clinics from 9 a.m. to 11 a.m. to gather the relevant information related to socio-demographic characteristics and history of UTI using tool III. The interview began with the researcher describing the goal of the study.

- Creating a distraction-free physical environment, as well as ensuring that each older adult is free from stress and suffering, will allow them to concentrate.

- The researcher used tool IV (Community-dwelling Older Adults' Knowledge about Preventive Practices of UTI Assessment Sheet) to assess the knowledge of older adults about preventive practices for UTI. The time of the interview ranged from 30 to 45 minutes depending on the level of understanding and cooperation of each older adult. It lasted nearly a month, from $1 / 11 / 2020$ to $30 / 11 / 2020$.

- The techniques of certain preventive practices of UTI, such as hygienic care and exercise performance, were assessed by the researcher using tool $\mathrm{V}$ (Communitydwelling Older Adults' UTI Preventive practices Checklist). This assessment was carried out by asking older adults to report the steps of hygienic care practices and types of exercises specific to UTI prevention.

- The proposed education nursing program was implemented in five (5) sessions once a week as follows:

- The first session: (introduction and basic information about UTI): the researcher was describing the significance of the intended education nursing program 
sessions as well as the expected aims to be met. Furthermore, the researcher provided basic and comprehensive information regarding UTI, such as its meaning, signs and symptoms, particularly atypical forms, complications, and the importance of its prevention.

- The second session (dietary requirements and adequate hydration) it includes health teaching about the importance of following a healthy diet to boost body immunity, focusing on essential elements required to decrease UTI. These elements include the following:

- Avoid spicy foods, fatty foods, and fast foods such as herring, salmon, Burger, and Pickles.

- High protein diet especially milk and milk products unless contraindicated.

- High vitamins such as $\mathrm{A}, \mathrm{B}$, and vitamin $\mathrm{C}$, which are found in the fruits and leafy vegetables.

- High minerals such as zinc and selenium, which are found in the liver, bananas, and omega 3 fatty acid.

- Decrease tea and caffeine consumption.

- Adequate fluid intake from 2000 to $2500 \mathrm{cc}$ per day to prevent dehydration and to increase washing out of bacteria by voiding, and take cranberry

juice to reduce

bacterial colonization.

- The third session (hygienic care practices and care of urinary catheter if present): it includes the following items:

- Proper technique of perineal care and its frequency.

- Proper technique of catheter care if present.

- Use of cotton under wears, and exposed it to sun rays.

- Use of shower rather than bathe in tub (Sitz bath).

- In this session, the researcher was displaying videos regarding optimal perineal care technique and urinary catheter for community-dwelling older adults.

- The fourth session (exercises) it includes the importance of exercise, types of exercises either isometric as kegel's exercise, bladder training or isotonic as walking, and principles of exercise in the prevention of UTI. These exercises include:

- Kegel's exercise to strength pelvic floor muscle.

- Bladder training program at least 5 to 7 times per day (Maclennon, 2010).

- Walking 20 to30 minutes at least 3 times per week.

- In this session, the researcher focused on age related-changes 
that may interfere with exercise performance, such as changes in vision, hearing, musculoskeletal, respiratory, and cardiovascular systems, and how to deal with these changes by taking a period of rest between exercises, starting exercise gradually and gently, and walking in clean, safe, and will lighted area.

- The fifth session (services available for follow up and referral): it includes the importance of follow-up, when and how to seek medical advice and referral services.

- The sessions were held in the waiting area of outpatient clinics; this area was prepared to be quiet, free from external noise, and not overcrowded. Each session lasted 30 to 45 minutes and began with a summary of what was taught in the previous session and the objectives of the next session.

- At the end of each session, the researcher leaves an unanswered question to encourage older adults to think deeply. Additionally, the researcher summarized and highlighted the key points in each session.

- Supportive techniques were applied by the researcher during each session, such as self-disclosure, giving information, clarifications, interpretations, suggestions, and guidance in a supportive manner.

III. Evaluation of the proposed education nursing program:

- Each older adult was assessed immediately after finishing the proposed education nursing program sessions using tool IV (Community-dwelling Older Adults' Knowledge about Preventive Practices of UTI Assessment Sheet) and tool V (Community-dwelling Older Adults' UTI Preventive Practices Checklist) and measured again after 6 weeks later using the same tools.

- In order to evaluate the effectiveness of the proposed education nursing program, the researcher compared the difference between pre-test and post-test scores of community-dwelling older adults.

- Collection of data covered a period of four months, from the beginning of November 2020 till the first of March 2021.

\section{Ethical considerations:}

An informed written consent was obtained from each study subject after clarification of the study purpose. Privacy of the study subjects and confidentiality of the collected data and anonymity was maintained. The participants were informed that participation in the study is voluntary and they can withdraw from the study at any time.

\section{Statistical Analysis}

After data collection, data was coded and transformed into specially designed forms as to be suitable for computer feeding and all entered data were verified for any error. Software IBM SPSS version 20.0 was used for the analysis statistical package of social science of the data, Descriptive statistics were done using numbers, percentages, arithmetic mean and standard deviation. Cronbach's alpha test was used to measure the reliability. Statistical analysis were done using significance test Chi square test. If 
more than $20 \%$ of the cells have expected values $<5$ and the level of significance was set as $\leq 0.05$.

Chi-square test used to categorical variables and to compare between different groups. Independent sample t-test used for comparing two independent samples. Paired sample T-test used to compares means from the same group at different times. Effect size used to determine program effect size Cohen d' was used $\left(\mathrm{eta}^{2}\right)$.

\section{Results}

The results of this study will be presented under the following parts:

Part (I): Socio-demographic characteristics and clinical data of the communitydwelling older adults:

Table (1) shows that the age of the study subjects ranged from 60 to 87 years with a mean of $68.31 \pm 3.09$ years, $52.0 \%$ of them aged 60 to less than 75 years, $52.0 \%$, were males, $64.0 \%$ were married, and $50.0 \%$ were illiterate. Less than one half $(48.0 \%)$ of the study subjects were housewives and the rest were either $20.0 \%$ employees, $18.0 \%$ had commercial work, or $14.0 \%$ had manual work, $82.0 \%$ didn't have current work, while only $18.0 \%$ of community-dwelling older adults still worked until now. The main source of income reported by $44.0 \%$ of the study subjects were pension. Less than two thirds $(60.0 \%)$ of the study subjects reported that they had no enough income and $80.0 \%$ of the study subjects were living in urban areas.

Table (2) illustrates that $52.0 \%$ of the community-dwelling older adults had chronic diseases, while $48.0 \%$ did not suffer from any disease. Hypertension was the most common disorder $(65.4 \%)$ among the study subjects. This is followed by $(42.3 \%)$ of older adults suffered from either musculoskeletal (osteoporosis and osteoarthritis) or genitourinary disorders (renal stones and benign prostatic hyperplasia). Those who had cardiovascular diseases were represented by $38.5 \%$, while respiratory diseases constituted 26.9\%. Endocrine and GIT diseases were reported by $30.8 \%$ of the community- dwelling-older adults.

In relation to prescribed medications, $65.4 \%$ of the study subjects consumed antihypertensive drugs, followed by $61.5 \%$ used cardiovascular drugs. More than one half $(53.8 \%)$ of the study subjects consumed anti-inflammatory drugs. Bronchodilators were consumed by $26.9 \%$, while $30.8 \%$ of the study subjects were consumed hypoglycemic agents and GIT drugs.

Table (3) reflects that $86.0 \%$ of the study subjects had no previous history of UTI while the rest (14.0\%) had previous UTI, of those, $71.4 \%$ previously had UTI since 6 to $\geq 8$ years ago. More than one half $(57.1 \%)$ of those who had a UTI reported that they had never been hospitalized for this reason before and $90.0 \%$ of the study subjects reported that they had no urological surgeries.

Table (4) reveals that the study subjects had no hearing problems were $94.0 \%$, while the rest had hearing problems and used hearing aids. The table also shows that $88.0 \%$ of the study subjects had no visual problems, and $12.0 \%$ suffered from visual problems and used eye glasses. More than three quarters $(80.0 \%)$ of the communitydwelling older adults walk unaided, while the rest $(20.0 \%)$ walk with assistance and use cane.

Part (II): The effect of education nursing program on preventive practices of urinary tract infection among community-dwelling older adults:

Table (5) indicates the effect of the proposed education nursing program on knowledge level regarding UTI among community-dwelling older adults. It revealed significant improvements in the level of knowledge in all areas of UTI were observed immediately post-program and six weeks later, with statistically significant variations; its definition $\left(X^{2}=123.34\right.$ $\mathrm{P}=0.000)$, types $\left(\mathrm{X}^{2}=131.811 \quad \mathrm{P}=0.000\right)$, 
manifestations $\left(\mathrm{X}^{2}=103.83 \mathrm{P}=0.000\right)$, risk factors $\left(\mathrm{X}^{2}=132.63 \mathrm{P}=0.000\right)$, complications $\left(\mathrm{X}^{2}=113.62 \quad \mathrm{P}=0.000\right), \quad$ treatment $(\mathrm{X} 2=123.45 \mathrm{P}=0.000)$, and preventive measures $\left(\mathrm{X}^{2}=159.43 \quad \mathrm{P}=0.000\right)$. Whereas, there was no significant effect of the proposed program noted in the area of knowledge related to the high risk group of UTI $\left(\mathrm{X}^{2}=7.535 \mathrm{P}=0.274\right)$. Moreover, six weeks post-program, the knowledge level of the study subjects was slightly decreased but still better than its level prior to the application of the program.

Table (6) displays the effect of the proposed education nursing program on practice level regarding UTI among community-dwelling older adults. It demonstrated that a good level of practice in all areas of UTI was seen immediately postprogram and six weeks later when compared to its level before starting the program. The differences were statistically significant; drinking adequate fluid $\left(X^{2}=124.26\right.$ $\mathrm{P}=0.000$ ), consuming a healthy diet $\left(\mathrm{X}^{2}=100.07 \quad \mathrm{P}=0.000\right)$, doing exercises $\left(\mathrm{X}^{2}=101.141 \mathrm{P}=0.000\right)$, following the steps of perineal care $\left(\mathrm{X}^{2}=115.81 \mathrm{P}=0.000\right)$, and seeking medical follow-up \& referral services $\left(X^{2}=50.009 P=0.000\right)$. Furthermore, six weeks after the program's implementation, the study subjects' practice level was slightly reduced but still better than it had been before the program's implementation.

Table (7) reveals the effect size of the education nursing program on preventive practices of UTI among communitydwelling older adults. It is possible to conclude that the proposed program had a highly significant effect on the preventive practices of UTI among the study subjects (0.96) for knowledge and (0.91) for practice. For more clarification, after implementing the proposed program, the mean score of community-dwelling older adults' knowledge level was $(18.92 \pm 1.747)$ compared to its mean score prior to the application of the program $(4.520 \pm 2.401)$. Additionally, after executing the proposed program, the practice level of the study subjects had a higher mean score $(3.74 \pm 0.89)$ than its previous mean score $(0.36 \pm 0.56)$.

Part (III): Relation between communitydwelling older adults' socio-demographic characteristics \& health history and their preventive practices of urinary tract infection:

Table (8) illustrates that there was a significant relation between the study subjects' level of education and their knowledge level only $(\mathrm{F}=3.293 \mathrm{P}=0.053)$. On the other hand, it noticed that the relations between the socio-demographic characteristics and the study subjects' practice level were not statistically significant; age $(\mathrm{F}=0.599 \mathrm{P}=0.554)$, sex $(\mathrm{t}=2.828 \mathrm{P}=0.099)$, marital status $(\mathrm{F}=0.401$ $\mathrm{P}=0.672)$, level of education $\quad(\mathrm{F}=0.033$ $\mathrm{P}=0.968)$, current work status $(\mathrm{t}=0.305$ $\mathrm{P}=0.583)$, adequacy of income $(\mathrm{F}=0.508$ $\mathrm{P}=0.605)$, and the place of residence $(\mathrm{t}=0.324 \quad \mathrm{P}=0.572)$.

Table (9) shows that there were statistically significant relations between chronic medical disorders, prescribed medications and the study subjects' knowledge level $(\mathrm{F}=5.994 \mathrm{P}=0.000, \mathrm{~F}=9.226$ $\mathrm{P}=0.000)$ respectively. Similar results were observed at the practice level of study subjects $\quad(\mathrm{F}=10.698 \quad \mathrm{P}=0.000, \quad \mathrm{~F}=14.550$ $\mathrm{P}=0.000)$ respectively.

\section{Discussion}

Urinary tract infection (UTI) is the most common bacterial infection in the elderly population (Rodriguez-Mañas, 2020). UTI can range in its severity from mild selflimiting illness to severe sepsis, with a mortality rate of $20-40 \%$ (Gharbi et al., 2019). UTI is a condition that is ignored by health-care providers. It can, however, be avoided if important measures are taken when caring for the elderly in the community. These measures assist them in understanding and adhering to effective UTI preventative measures (Gaurav et al., 2019). In this regard, knowledge and practices 
regarding UTI prevention should be a priority for future intervention programs to promote specific practices for UTI prevention. (Mody et al., 2018).

Thus, the aim of this study is to determine the effect of education nursing program on preventive practices of urinary tract infection among community-dwelling older adults.

The proposed education nursing program is a crucial non-pharmacological intervention for UTI. It is a comprehensive package of preventive practices that includes, but is not restricted to, health education and nursing interventions, with the goal of reducing morbidity and mortality, avoiding negative consequences, reducing recurring infection, and enhancing quality of life (Fathy et al., 2019).

The proposed education nursing program used in the current study is a package of nursing education and interventions offered in a five-session, one-session-per-week, and focused on a comprehensive assessment of older adults, followed by personalized preventive practices such as basic information about UTI, a balanced and healthy diet, adequate fluid intake, and hygienic care practices (Fathy et al., 2019). Furthermore, proper exercises as kegel's exercise, bladder training, and walking are recommended. In addition, medical followup and referral services are emphasized (Nicolle et al., 2018).

Fortunately, the main results of the current study indicated that the proposed program had a significant effect on the knowledge level of community-dwelling older adults in all areas of UTI knowledge, including the meaning of UTI, its types, clinical manifestations, particularly atypical symptoms, risk factors, complications, and treatment. The knowledge level of community-dwelling older adults improved immediately after the program implementation and six weeks later (Table 5). This improvement could be attributed to the researcher's use of a well-developed and structured education program that included comprehensive and illustrated printed materials with clearly defined goals.

These goals were covered in five (5) sessions, each with a set of specific objectives and illustrated, colored pictures to cover the important instructional points related to urinary system function, agerelated changes, the expected causes of UTI, and warning signs that require prompt treatment and regular follow-up. This assists community-dwelling older adults in understanding and mastering their health status.

Because health education is thought to be an important aspect of UTI prevention, the researcher attempted to overcome the age-related changes that may impede the teaching process for older adults. This is achieved by speaking clearly and loudly while offering concise and specific information. Furthermore, the researcher repeats instructions and accommodates the educational materials to address visual deficits associated with the aging process (large printed materials and attractive colored pictures). Another possible cause for improvement in study subjects' knowledge level regarding UTI prevention is the researcher used effective communication techniques such as respecting personal space, listening attentively, allowing ample time for older adults to respond, and often encouraging feedback.

To some extent, the researchers tried to limit environmental noise and give multisensory stimulation by activating older adults' senses, such as vision through watching videos about the program contents. This in turn improved the cognitive ability of older adults, facilitating the learning process and helping them acquire information more easily.

This finding of the present study is in congruence with El-magrabi \& Rashad, (2010); Cooper et al., (2017), in the United Kingdom, and Jena et al., (2020), in the United States, who reported that older adults' 
knowledge regarding UTI prevention improved significantly with a simple educational program when compared to the start of the study, while the current study findings contradict those of a study by Jones et al., (2019), who found that there was no statistically significant difference in knowledge level before and after the education program.

A notable finding of the present study revealed that there was a significant progress in community-dwelling older adults' practices level regarding UTI prevention immediately after the implementation of the proposed education nursing program and six week later (Table 6). This progress can be explained by the fact that practicing preventive measures can enable older adults to realize the health problem process, and, subsequently, enhance their own confidence in managing their condition. Moreover, the practices learnt through the proposed education nursing program address all areas of preventive practices regarding UTI, such as encouraging them to drink adequate fluid, eat a healthy diet, and doing proper exercises as well as following steps for perineal care, and seeking medical followup.

In addition to providing handouts to older adults as a permanent and simple source of information, the researcher prepared and displayed videos about proper techniques for perineal care and urinary catheter management. The researcher asks the older adults to recall the steps of procedures demonstrated in these videos. It is essential to mention the role of family members in assisting community-dwelling older adults in adhering to and following the steps and measures of UTI prevention. In the current study, approximately two-thirds of older persons in Damanhur city were married and lived with their spouses and families as a tradition (Table 1). They look after each other and remind themselves to drink plenty of fluids, eat a balanced \& healthy diet, and follow the prescribed hygienic care instructions. All of these affect positively their UTI prevention practices.

This result of the present study supported by the results of Grealish et al., (2020), which found that educational interventions were successful in enhancing older adults' practices of UTI prevention. Moreover, this finding is consistent with that of another study conducted in England by (Joseph, 2021), which found that older people had a greater degree of good practice after participating in continuing nursing education programs than previously. Another study done by (ElLawindi, 2014) in Giza, Egypt, revealed that there is a significant relation between continuing education nursing programs and preventive practices regarding UTI.

In terms of community-dwelling older adults' knowledge and practices regarding UTI after 6 weeks of the program implementation, it can be seen that following preventive practices regarding UTI were slightly reduced when compared to their level immediately after the implementation of the proposed education nursing program, but they were still higher than prior to the implementation of the program and the variations were statistically significant (Tables 5 and 6). This could be attributed to the fact that the acquired knowledge, behaviors, and practices decline with the passage of time, especially in the absence or decreased continuous follow-up and supervision. This is in congruence with Bazzaz et al., (2021), who stated that older adults' knowledge and practices addressing UTI prevention improved from preeducation to post-education, but dropped slightly later.

One of the sound findings of this study is that the proposed education nursing program had a large size effect on UTI preventive practices (0.96) for knowledge and (0.91) for practices (Table 7). This suggests that significant progress in the knowledge of community-dwelling older adults was reflected in their practices, with those who were more educated about their illness 
having more trust in their ability to manage their own health concerns. This is in the same line as Jena et al., (2020), who stated that nursing education had a greater impact on older adults' knowledge level regarding UTI prevention than on their behavior and practice.

In this regard, one of the most important reasons for the proposed program's improvement was the long period of individual interaction between the researcher and the study subjects, during which preventive practice principles were achieved, providing successful experience in managing health problems, and giving older adults confidence in finding new measures in a supportive and positive environment. Furthermore, the researcher provided the proposed teaching to the study subjects via phone calls in order to facilitate follow-up when older adults are present in their own homes. Additionally, the researcher prepared cranberry juice and distributed it to study participants in order to encourage them to consume it at home due to its great benefits in preventing UTI (Fu et al., 2017).

A considerable rational for the large effect of the proposed program on the knowledge of study participants study participants (Table 7) was revealed by one finding of the current study that more than half of them were young old (aged 60 years to less than 75 years) with fewer senescent changes that may not hinder the learning process of older adults (table 1).

Furthermore, the current study found that one-half of the study participants had completed either their primary or secondary education (table 1). Both levels of education can help patients improve their knowledge, abilities, and attitudes toward their health issues and how to manage them. Older adults who are well-educated can take control of their illness and improve their capacity to follow directions and the instructions given to them (Table 8). This result is consistent with the findings of other studies conducted in the United States by Sihra et al., (2018), and Woodford \& George
(2011) who found that level of education, influenced the knowledge of UTI preventive practices. However, the result of the present study contradicts the findings of Lee et al., (2018), in China, who reported that there is no significant relation between education and knowledge level regarding UTI preventive practices.

Additionally, nearly one-half $(48.0 \%)$ of the study participants did not have any medical disorders (Table 2), indicating that they were still capable of performing selfcare practices related to UTI prevention. The majority of them did not have sensory impairments, both visual and hearing (Table 4), allowing the study subjects to benefit from the colored pictures and printed materials provided in the proposed program. Another probable reason for the improvement of community-dwelling older adults' UTI preventive practices is that the majority of them walk unaided (Table 4), allowing them to perform recommended exercises such as kegel's exercise, bladder training, and walking, all of which are included in the proposed program. Furthermore, the current study reported that there were statistically significant relation between chronic medical disorders, prescribed medications and the study subjects' knowledge level \& the practice level (Table 9). This is in congruence with a study done in Europe by Wojszel \& Silkiewicz (2018), Grealish et al., (2020), who reported that there was a significant relation between health status of older adults and their preventive practices.

To the best of our knowledge, this is the first study in Alexandria, Egypt, to directly focus on the effect of nursing education on knowledge and practice levels regarding UTI among community-dwelling older adults, as well as to develop a comprehensive educational Arabic-version material for teaching the concept of preventive practices to those older adults and subsequently determining the effect of the proposed program. Hence, according to the results of the present study, the proposed 
hypothesis is approved, which is that community-dwelling older adults who attend the proposed education nursing program achieve higher post-test scores on UTI preventive practices than before.

\section{Conclusion}

From the findings of the present study, it can be concluded that the application of the proposed education nursing program was proved to be effective in enhancing the knowledge and practices regarding urinary tract infection (UTI) among communitydwelling older adults, with a highly significant effect size and statistically significant differences between the prior to and immediately after the program. This improvement has been regretted over time (six weeks post-program), but is still better than before.

\section{Recommendations}

Based on the findings of the present study, the following recommendations are: suggested:

\section{A) Recommendations geared to community-dwelling older adults:}

- Educational materials about UTI prevention, including a printed handout and colored brochures, should be designed and distributed among community-dwelling older adults and their caregivers in all health care settings, including residential homes, hospitals, and outpatient clinics. This assists older adults in adhering to the principles of UTI prevention and skills required for self-care management.

- 2- A written UTI preventive practice guidelines should be developed by an interdisciplinary team comprised of physicians, gerontological nurses, and other health care providers for managing UTI in outpatient clinics for older adults. These guidelines should be reviewed and updated on a regular basis.

\section{B) Recommendations geared to nursing staff:}

- The proposed education nursing program regarding UTI preventive practices should implemented and adopted as a part of routine nursing care in inpatient units and outpatient clinics by nurses and other health care providers.

- In-service training programs for nursing staff in inpatient units and outpatient clinics should be designed and delivered on a regular basis to update their knowledge and enhance their performance regarding UTI. The training should cover the most recent techniques for preventing UTI, identifying its atypical manifestations, and its detrimental effects on older adults' health. This program can be offered online to save time during working hours.

\section{C) The future researches in this field could include:}

- The effect of self-care strategies on the quality of life of communitydwelling older adults suffering from urinary tract infection.

\section{Acknowledgement}

The researchers are thankful to all geriatric patients agreed to participate in this study. Deepest gratitude also goes to the head of the outpatient clinics at Damanhour National Medical Institute, El Behera Governorate, Egypt, for approval to conduct the study. 
Table (1): Distribution of the community-dwelling older adults according to their sociodemographic characteristics

\begin{tabular}{|c|c|c|}
\hline \multirow{2}{*}{ Socio-demographic characteristics } & \multicolumn{2}{|c|}{ The study subjects (no.=50) } \\
\hline & no. & $\%$ \\
\hline Age (in years) & & \\
\hline $60-$ & 26 & 52.0 \\
\hline 75- & 17 & 34.0 \\
\hline$\geq 85$ & 7 & 14.0 \\
\hline Mean \pm SD & \multicolumn{2}{|c|}{$68.31 \pm 3.09$ years } \\
\hline Sex & & \\
\hline Male & 26 & 52.0 \\
\hline Female & 24 & 48.0 \\
\hline Marital status & & \\
\hline Married & 32 & 64.0 \\
\hline Divorced & 14 & 28.0 \\
\hline Widow & 4 & 8.0 \\
\hline Level of education & & \\
\hline Illiterate & 25 & 50.0 \\
\hline Basic education & 14 & 28.0 \\
\hline Secondary education & 11 & 22.0 \\
\hline Work before retirement & & \\
\hline Housewives & 24 & 48.0 \\
\hline Employee & 10 & 20.0 \\
\hline Commercial work & 9 & 18.0 \\
\hline Manual work & 7 & 14.0 \\
\hline Current Work status & & \\
\hline Not working & 41 & 82.0 \\
\hline Working & 9 & 18.0 \\
\hline Source of income & & \\
\hline Pension & 22 & 44.0 \\
\hline Social affairs & 15 & 30.0 \\
\hline Current work & 9 & 18.0 \\
\hline Family members & 4 & 8.0 \\
\hline Adequacy of income & & \\
\hline Not enough & 30 & 60.0 \\
\hline Enough & 20 & 40.0 \\
\hline Place of residence & & \\
\hline Urban & 40 & 80.0 \\
\hline Rural & 10 & 20.0 \\
\hline
\end{tabular}


Table (2): Distribution of the community-dwelling older adults according to their health history

\begin{tabular}{||l|c|c||}
\hline \multirow{2}{*}{ Health history } & \multicolumn{2}{|c|}{ The study subjects (no.=50) } \\
\cline { 2 - 3 } Presence of chronic diseases & no. & $\mathbf{\%}$ \\
No & $\mathbf{2 4}$ & $\mathbf{4 8 . 0}$ \\
Yes & $\mathbf{2 6}$ & $\mathbf{5 2 . 0}$ \\
Type of chronic diseases\# & & 65.4 \\
Hypertension & 17 & 42.3 \\
Musculoskeletal diseases & 11 & 42.3 \\
Genitourinary diseases & 11 & 38.5 \\
Cardiovascular diseases & 10 & 26.9 \\
Respiratory disease & 7 & 30.8 \\
Others (Endocrine \& GIT diseases) & 8 & 65.4 \\
Prescribed medication & & 61.5 \\
Antihypertensive & 17 & 53.8 \\
Cardiovascular drugs & 16 & 26.9 \\
Anti-inflammatory/analgesics & 14 & 30.8 \\
Bronchodilators & 7 & 8 \\
Others (hypoglycemic agents \& GIT drugs) & & \\
\hline
\end{tabular}

\# Multiple responses were allowed

Table (3): Distribution of the community-dwelling older adults according to their urological history

\begin{tabular}{||l|c|c||}
\hline \multirow{2}{*}{ Urological history } & \multicolumn{2}{|c||}{ The study subjects (no.=50) } \\
\cline { 2 - 3 } Previous history of UTI & no. & $\mathbf{\%}$ \\
No & & $\mathbf{4 3}$ \\
Yes & $\mathbf{7 3 . 0}$ \\
Onset of previous UTI / year & 1 & $\mathbf{1 4 . 0}$ \\
$2-$ & 1 & 14.3 \\
$4-$ & 5 & 14.3 \\
6- $\geq 8$ & & 71.4 \\
\hline Previous hospitalization due to UTI- & 4 & 57.1 \\
No & 3 & 42.9 \\
Yes & & \\
Previous urological surgeries- & 45 & 90.0 \\
No & 5 & 10.0 \\
Yes & & \\
\hline \hline
\end{tabular}

Table (4): Distribution of the community-dwelling older adults according to their physical status

\begin{tabular}{|l|c|c||}
\hline \multirow{2}{*}{ Physical status } & \multicolumn{2}{|c|}{ The study subjects (no.=50) } \\
\cline { 2 - 3 } Hearing status & no. & \% \\
No hearing problems & 47 & 94.0 \\
Hearing problems and use hearing aids & 3 & 6.0 \\
\hline Visual status & 44 & 88.0 \\
No visual problems & 6 & 12.0 \\
Visual problems and use eye glasses & 40 & 80.0 \\
\hline Level of mobility & 10 & 20.0 \\
Walk unaided & & \\
Walk with assistance and use assisting device as & & \\
cane & & \\
\hline
\end{tabular}


Table (5): The effect of the proposed education nursing program on knowledge level regarding UTI among community-dwelling older adults immediately post-program and 6 weeks post-program

\begin{tabular}{|c|c|c|c|c|c|c|c|}
\hline \multirow[t]{2}{*}{$\begin{array}{l}\text { Community- dwelling older } \\
\text { adults' knowledge level }\end{array}$} & \multicolumn{2}{|c|}{$\begin{array}{c}\text { Baseline } \\
\text { (pre-program) }\end{array}$} & \multicolumn{2}{|c|}{$\begin{array}{c}\text { Immediately } \\
\text { (post- } \\
\text { program) } \\
\end{array}$} & \multicolumn{2}{|c|}{$\begin{array}{l}6 \text { weeks } \\
\text { (post- } \\
\text { program) }\end{array}$} & \multirow[t]{2}{*}{ Test of significance } \\
\hline & no. & $\%$ & no. & $\%$ & no. & $\%$ & \\
\hline \multicolumn{7}{|l|}{ Definition of UTI } & \multirow{4}{*}{$\begin{array}{c}\mathrm{P}=0.000^{*} \\
\mathrm{X}^{2}=123.34\end{array}$} \\
\hline \multirow{3}{*}{$\begin{array}{l}\text { Poor } \\
\text { Fair } \\
\text { Good }\end{array}$} & 27 & 54.0 & 0 & 0.0 & 0 & 0.0 & \\
\hline & 22 & 44.0 & 1 & 2.0 & 6 & 12.0 & \\
\hline & 1 & 2.0 & 49 & 98.0 & 44 & 88.0 & \\
\hline \multicolumn{8}{|l|}{ High risk group } \\
\hline \multirow{3}{*}{$\begin{array}{l}\text { Poor } \\
\text { Fair } \\
\text { Good }\end{array}$} & 33 & 66.0 & 0 & 0.0 & 1 & 2.0 & \multirow{3}{*}{$\begin{array}{l}\mathrm{P}=0.274 \\
\mathrm{X}^{2}=7.535\end{array}$} \\
\hline & 17 & 34.0 & 4 & 8.0 & 19 & 38.0 & \\
\hline & 0 & 0.0 & 46 & 92.0 & 30 & 60.0 & \\
\hline \multicolumn{8}{|l|}{ Types of UTI } \\
\hline \multirow{3}{*}{$\begin{array}{l}\text { Poor } \\
\text { Fair } \\
\text { Good }\end{array}$} & 44 & 88.0 & 0 & 0.0 & 0 & 0.0 & \multirow{3}{*}{$\begin{aligned} P & =0.000^{*} \\
X^{2} & =131.811\end{aligned}$} \\
\hline & 5 & 10.0 & 4 & 8.0 & 9 & 18.0 & \\
\hline & 1 & 2.0 & 46 & 92.0 & 41 & 82.0 & \\
\hline \multicolumn{8}{|l|}{ Manifestation of UTI } \\
\hline \multirow{3}{*}{$\begin{array}{l}\text { Poor } \\
\text { Fair } \\
\text { Good }\end{array}$} & 22 & 44.0 & 0 & 0.0 & 0 & 0.0 & \multirow{3}{*}{$\begin{array}{c}\mathrm{P}=0.000^{*} \\
\mathrm{X}^{2}=103.83\end{array}$} \\
\hline & 26 & 52.0 & 2 & 4.0 & 15 & 30.0 & \\
\hline & 2 & 4.0 & 48 & 96.0 & 35 & 70.0 & \\
\hline \multicolumn{8}{|l|}{ Risk factors of UTI } \\
\hline \multirow{3}{*}{$\begin{array}{l}\text { Poor } \\
\text { Fair } \\
\text { Good }\end{array}$} & 37 & 74.0 & 0 & 0.0 & 0 & 0.0 & \multirow{3}{*}{$\begin{array}{c}\mathrm{P}=0.000^{*} \\
\mathrm{X}^{2}=132.63\end{array}$} \\
\hline & 12 & 24.0 & 8 & 16.0 & 31 & 62.0 & \\
\hline & 1 & 2.0 & 42 & 84.0 & 19 & 38.0 & \\
\hline \multicolumn{8}{|l|}{ Complications of UTI } \\
\hline \multirow{3}{*}{$\begin{array}{l}\text { Poor } \\
\text { Fair } \\
\text { Good }\end{array}$} & 32 & 64.0 & 0 & 0.0 & 0 & 0.0 & \multirow{3}{*}{$\begin{array}{c}\mathrm{P}=0.000^{*} \\
\mathrm{X}^{2}=113.62\end{array}$} \\
\hline & 18 & 36.0 & 5 & 10.0 & 17 & 34.0 & \\
\hline & 0 & 0.0 & 45 & 90.0 & 33 & 66.0 & \\
\hline \multicolumn{8}{|l|}{ Treatment of UTI } \\
\hline \multirow{3}{*}{$\begin{array}{l}\text { Poor } \\
\text { Fair } \\
\text { Good }\end{array}$} & 41 & 82.0 & 0 & 0.0 & 0 & 0.0 & \multirow{3}{*}{$\begin{array}{c}\mathrm{P}=0.000^{*} \\
\mathrm{X}^{2}=123.45\end{array}$} \\
\hline & 9 & 18.0 & 26 & 52.0 & 38 & 76.0 & \\
\hline & 0 & 0.0 & 24 & 48.0 & 12 & 24.0 & \\
\hline Preventive measures of UTI & & & & & & & \\
\hline Poor & 49 & 98.0 & 0 & 0.0 & 0 & 0.0 & \\
\hline Fair & 1 & 2.0 & 0 & 0.0 & 9 & 18.0 & $\mathrm{P}=0.000^{*}$ \\
\hline Good & 0 & 0.0 & 50 & 100.0 & 41 & 82.0 & $X^{2}=159.43$ \\
\hline Total older adults' Knowled & & & & & & & \\
\hline Poor & 49 & 98.0 & 0 & 0.0 & 0 & 0.0 & \\
\hline Fair & 1 & 2.0 & 0 & 0.0 & 6 & 12.0 & $\mathrm{P}=0.000^{*}$ \\
\hline Good & 0 & 0.0 & 50 & 100.0 & 44 & 88.0 & $X^{2}=154.43$ \\
\hline
\end{tabular}


Table (6): The effect of the proposed education nursing program on practice level regarding UTI among community-dwelling older adults immediately post-program and 6 weeks post-program

\begin{tabular}{|c|c|c|c|c|c|c|c|}
\hline \multirow[t]{2}{*}{$\begin{array}{l}\text { Community- dwelling } \\
\text { older adults' practice level }\end{array}$} & \multicolumn{2}{|c|}{$\begin{array}{l}\text { Baseline } \\
\text { (pre- } \\
\text { program) }\end{array}$} & \multicolumn{2}{|c|}{$\begin{array}{c}\text { Immediately } \\
\text { (post- } \\
\text { program) }\end{array}$} & \multicolumn{2}{|c|}{$\begin{array}{c}6 \text { weeks } \\
\text { (post- } \\
\text { program) }\end{array}$} & \multirow[t]{2}{*}{$\begin{array}{c}\text { Test of } \\
\text { significance }\end{array}$} \\
\hline & no. & $\%$ & no. & $\%$ & no. & $\%$ & \\
\hline \multicolumn{8}{|l|}{ Drinking adequate fluid } \\
\hline \multirow{2}{*}{$\begin{array}{l}\text { Poor } \\
\text { Good }\end{array}$} & 46 & 92.0 & 0 & 0.0 & 2 & 4.0 & \multirow{2}{*}{$\begin{array}{c}\mathrm{P}=0.000^{*} \\
\mathrm{X}^{2}=124.26\end{array}$} \\
\hline & 4 & 8.0 & 50 & 100.0 & 48 & 96.0 & \\
\hline \multicolumn{8}{|l|}{ Consuming a healthy diet } \\
\hline \multirow{2}{*}{$\begin{array}{l}\text { Poor } \\
\text { Good }\end{array}$} & 50 & 100.0 & 0 & 0.0 & 24 & 48.0 & \multirow{2}{*}{$\begin{aligned} \mathrm{P} & =0.000^{*} \\
\mathrm{X}^{2} & =100.07\end{aligned}$} \\
\hline & 0 & 0.0 & 50 & 100.0 & 26 & 52.0 & \\
\hline \multicolumn{8}{|l|}{ Practicing exercises } \\
\hline Poor & 50 & 100.0 & 0 & 0.0 & 21 & 42.0 & \multirow{2}{*}{$\begin{aligned} \mathrm{P} & =0.000^{*} \\
\mathrm{X}^{2} & =101.141\end{aligned}$} \\
\hline Good & 0 & 0.0 & 50 & 100.0 & 29 & 58.0 & \\
\hline \multicolumn{8}{|c|}{ Following the steps of perineal care } \\
\hline Poor & 48 & 96.0 & 0 & 0.0 & 7 & 14.0 & \multirow{2}{*}{$\begin{aligned} \mathrm{P} & =0.000^{*} \\
\mathrm{X}^{2} & =115.81\end{aligned}$} \\
\hline Good & 2 & 4.0 & 50 & 100.0 & 43 & 86.0 & \\
\hline \multicolumn{8}{|c|}{ Seeking medical Follow up and referral services } \\
\hline Poor & 38 & 76.0 & 8 & 16.0 & 9 & 18.0 & \multirow{2}{*}{$\begin{aligned} \mathrm{P} & =0.000^{*} \\
\mathrm{X}^{2} & =50.009\end{aligned}$} \\
\hline Good & 12 & 24.0 & 42 & 84.0 & 41 & 82.0 & \\
\hline \multicolumn{8}{|c|}{ Total older adults' practice level } \\
\hline \multirow{2}{*}{$\begin{array}{l}\text { Poor } \\
\text { Good }\end{array}$} & 50 & 100.0 & 0 & 0.0 & 0 & 0.0 & \multirow{2}{*}{$\begin{array}{c}\mathrm{P}=0.000^{*} \\
\mathrm{X}^{2}=150.00\end{array}$} \\
\hline & 0 & 0.0 & 50 & 100.0 & 50 & 100.0 & \\
\hline
\end{tabular}

$X^{2}=$ Chi Square test

$X^{2}$ comparisons in the same group across the days

$X a^{2}$ comparison between the baseline and the second day

$X^{b 2}$ comparison between the baseline and the third day

$X^{c 2}$ comparison between the second and the third day

*Significant $p$ at $\leq 0.05$

Table (7): The effect size of the education nursing program on preventive practices of UTI among the community-dwelling older adults

\begin{tabular}{|c|c|c|c|}
\hline \multirow{3}{*}{$\begin{array}{l}\text { Community- dwelling } \\
\text { older adults' Preventive } \\
\text { practices }\end{array}$} & \multicolumn{2}{|c|}{ The study subjects $($ no. $=50)$} & \multirow{3}{*}{ Effect size } \\
\hline & $\begin{array}{c}\text { Baseline } \\
\text { (Pre-program) }\end{array}$ & $\begin{array}{c}\text { Follow up } \\
\text { (post-program) }\end{array}$ & \\
\hline & Mean \pm SD & Mean \pm SD & \\
\hline Knowledge & $4.520 \pm 2.401$ & $18.92 \pm 1.747$ & 0.96 \\
\hline Practices & $0.36 \pm 0.56$ & $3.74 \pm 0.89$ & 0.91 \\
\hline
\end{tabular}


Table (8): The relation between community-dwelling older adults' socio-demographic characteristics and their knowledge level \& practice level regarding UTI

\begin{tabular}{|c|c|c|c|c|}
\hline \multirow{2}{*}{$\begin{array}{l}\text { Socio-demographic } \\
\text { characteristics }\end{array}$} & \multicolumn{2}{|c|}{$\begin{array}{c}\text { Community- dwelling older adults' } \\
\text { knowledge level }\end{array}$} & \multicolumn{2}{|c|}{$\begin{array}{c}\text { Community- dwelling older adults' } \\
\text { practice level }\end{array}$} \\
\hline & $\mathrm{M} \pm \mathrm{SD}$ & Test of significance & $\mathrm{M} \pm \mathrm{SD}$ & Test of significance \\
\hline \multirow{3}{*}{$\begin{array}{l}\text { Age (in years) } \\
60- \\
75- \\
\geq 85\end{array}$} & $22.15 \pm 1.255$ & \multirow{3}{*}{$\begin{array}{l}F=1.593 \\
P=0.214\end{array}$} & $4.885 \pm 0.325$ & \multirow{3}{*}{$\begin{array}{l}F=0.599 \\
P=0.554\end{array}$} \\
\hline & $22.76 \pm 1.147$ & & $4.823 \pm 0.393$ & \\
\hline & $22.00 \pm 1.291$ & & $4.714 \pm 0.487$ & \\
\hline \multirow{2}{*}{$\begin{array}{l}\text { Sex } \\
\text { Male } \\
\text { Female }\end{array}$} & $22.38 \pm 1.202$ & \multirow{2}{*}{$\begin{array}{l}\mathrm{t}=0.069 \\
\mathrm{P}=0.749\end{array}$} & $4.923 \pm 0.272$ & \multirow{2}{*}{$\begin{array}{l}\mathrm{t}=2.828 \\
\mathrm{P}=0.099\end{array}$} \\
\hline & $22.29 \pm 1.301$ & & $4.750 \pm 0.442$ & \\
\hline \multirow{3}{*}{$\begin{array}{l}\text { Marital status } \\
\text { Married } \\
\text { Divorced } \\
\text { Widow }\end{array}$} & $22.46 \pm 1.344$ & \multirow{3}{*}{$\begin{array}{l}F=0.502 \\
P=0.609\end{array}$} & $4.875 \pm 0.336$ & \multirow{3}{*}{$\begin{array}{l}F=0.401 \\
P=0.672\end{array}$} \\
\hline & $22.25 \pm 0.500$ & & $4.750 \pm 0.500$ & \\
\hline & $22.07 \pm 1.141$ & & $4.786 \pm 0.426$ & \\
\hline \multirow{3}{*}{$\begin{array}{l}\text { Level of education } \\
\text { Illiterate } \\
\text { Basic education } \\
\text { Secondary education }\end{array}$} & $22.44 \pm 1.227$ & & $4.840 \pm 0.374$ & \multirow{3}{*}{$\begin{array}{l}F=0.033 \\
P=0.968\end{array}$} \\
\hline & $22.78 \pm 1.051$ & & $4.857 \pm 0.363$ & \\
\hline & $21.54 \pm 1.213$ & & $4.818 \pm 0.404$ & \\
\hline \multirow{2}{*}{$\begin{array}{l}\text { Current Work status } \\
\text { Not working } \\
\text { Working }\end{array}$} & $22.39 \pm 1.263$ & & $4.854 \pm 0.357$ & \multirow{2}{*}{$\begin{array}{l}\mathrm{t}=0.305 \\
\mathrm{P}=0.583\end{array}$} \\
\hline & $22.11 \pm 1.166$ & $\mathrm{P}=0.546$ & $4.777 \pm 0.441$ & \\
\hline \multirow{2}{*}{$\begin{array}{l}\text { Adequacy of income } \\
\text { Enough } \\
\text { Not enough } \\
\end{array}$} & $22.55 \pm 1.338$ & \multirow{2}{*}{$\begin{array}{l}\mathrm{F}=0.470 \\
\mathrm{P}=0.628\end{array}$} & $4.888 \pm 0.323$ & \multirow{2}{*}{$\begin{array}{l}\mathrm{F}=0.508 \\
\mathrm{P}=0.605\end{array}$} \\
\hline & $22.20 \pm 1.215$ & & $4.800 \pm 0.406$ & \\
\hline \multirow{2}{*}{$\begin{array}{l}\text { Place of residence } \\
\text { Urban } \\
\text { Rural }\end{array}$} & $22.80 \pm 1.032$ & \multirow{2}{*}{$\begin{array}{l}\mathrm{t}=0.749 \\
\mathrm{P}=0.192\end{array}$} & $4.900 \pm 0.316$ & \multirow{2}{*}{$\begin{array}{l}\mathrm{t}=0.324 \\
\mathrm{P}=0.572\end{array}$} \\
\hline & $22.22 \pm 1.271$ & & $4.825 \pm 0.384$ & \\
\hline
\end{tabular}

$F=$ ANOVA test

Table (9): The relation between community-dwelling older adults' health history and their knowledge level, \& practice level regarding UTI

\begin{tabular}{|c|c|c|c|c|}
\hline \multirow[t]{2}{*}{ Health history } & \multicolumn{2}{|c|}{$\begin{array}{c}\text { Community- dwelling older adults' } \\
\text { knowledge level }\end{array}$} & \multicolumn{2}{|c|}{$\begin{array}{c}\text { Community-dwelling older adults' } \\
\text { practice level }\end{array}$} \\
\hline & $M \pm S D$ & Test of significance & $\mathrm{M} \pm \mathrm{SD}$ & Test of significance \\
\hline \multirow{6}{*}{$\begin{array}{l}\text { Type of chronic diseases } \\
\text { Respiratory diseases } \\
\text { Cardiovascular diseases } \\
\text { Others (endocrine } \\
\text { diseases\& GIT diseases) } \\
\text { Genitourinary diseases } \\
\text { Musculoskeletal diseases } \\
\text { Hypertension }\end{array}$} & $23.50 \pm 0.707$ & \multirow{6}{*}{$\begin{array}{c}\mathrm{F}=5.994 \\
\mathbf{P}=\mathbf{0 . 0 0 0 *}\end{array}$} & $5.000 \pm 0.000$ & \multirow{6}{*}{$\begin{array}{l}\mathrm{F}=10.698 \\
\mathbf{P}=\mathbf{0 . 0 0 0} *\end{array}$} \\
\hline & $22.50 \pm 0.707$ & & $4.500 \pm 0.707$ & \\
\hline & $22.46 \pm 0.562$ & & $4.500 \pm 0.000$ & \\
\hline & $22.16 \pm 0.656$ & & $4.346 \pm 0.240$ & \\
\hline & $22.15 \pm 1.472$ & & $4.200 \pm 0.102$ & \\
\hline & $22.00 \pm 0.000$ & & $4.000 \pm 0.000$ & \\
\hline \multirow{5}{*}{$\begin{array}{l}\text { Prescribed medication } \\
\text { Bronchodilators } \\
\text { Anti-inflammatory / } \\
\text { analgesics } \\
\text { Others (hypoglycemic } \\
\text { agent\& GIT drugs) } \\
\text { Cardiovascular drugs } \\
\text { Antihypertensive }\end{array}$} & $23.50 \pm 0.707$ & \multirow{5}{*}{$\begin{array}{l}F=9.226 \\
\mathbf{P}=\mathbf{0 . 0 0 0} *\end{array}$} & $4.875 \pm 0.353$ & \multirow{5}{*}{$\begin{array}{l}\mathrm{F}=14.550 \\
\mathbf{P}=\mathbf{0 . 0 0 0} *\end{array}$} \\
\hline & $22.75 \pm 1.282$ & & $4.384 \pm 0.295$ & \\
\hline & $22.46 \pm 0.953$ & & $4.250 \pm 0.357$ & \\
\hline & $22.25 \pm 0.707$ & & $4.200 \pm 0.102$ & \\
\hline & $22.00 \pm 0.000$ & & $3.505 \pm 0.707$ & \\
\hline
\end{tabular}




\section{References}

- Abelson, B., Sun, D., Que, L., Nebel, R. A., Baker, D., Popiel, P., Amundsen, C. L., Chai, T., Close, C., Disanto, M., Fraser, M. O., Kielb, S. J., Kuchel, G., Mueller, E. R., Palmer, M. H., Parker-Autry, C., Wolfe, A. J., \& Damaser, M. S. (2018). Sex differences in lower urinary tract biology and physiology. Biology of sex differences, 9 (1), 45.

- Alpay, Y., Aykin, N., Korkmaz, P., Gulduren, H. M., \& Caglan, F. C. (2018). Urinary tract infections in the geriatric patients. Pakistan Journal of Medical Sciences, 34 (1), 67-72.

- Biggel, M., Heytens, S., Latour, K., Bruyndonckx, R., Goossens, H., \& Moons P. (2019). Asymptomatic bacteriuria in older adults: the most fragile women are prone to long-term colonization. British Medical Care Geriatric Journal, 19, 170.

- Bliemel, C., Buecking, B., Hack, J., Aigner, R., Eschbach, D. A., Ruchholtz, S., \& Oberkircher, L. (2018). Urinary tract infection in patients with hip fracture: An underestimated event? Journal of Geriatrics and Gerontology International, 17(12), 2369-75.

- Bazzaz, B. S., Fork, S., Ahmadi, R, Khameneh B. (2021). Deep insights into urinary tract infections and effective natural remedies. African Journal of Urology, 27 (6), 11-5.

- Crnich, C. J., Jump, R. L., \& Nace, D. A. (2017). Improving Management of Urinary Tract Infections in Older Adults: A Paradigm Shift or Therapeutic Nihilism? Journal of the American Geriatrics Society, 65(8), 1661-166.

- Coker, T. J., \& Dierfeldt, D. M. (2016). Acute Bacterial Prostatitis: Diagnosis and Management. American physician, 93 (2), 114-20.

- Center for Disease Control and Prevention (CDC). (2021). Catheter-associated urinary tract infection and non- catheter associated urinary tract infection. National Health care and Safety Network, 15 (2) 1-15.
- Clayson, D., Wild, D., Doll, H., Keating, K., \& Gondek, K. (2004). Validation of a patient-administered questionnaire to measure the severity and bothersomeness of lower urinary tract symptoms in uncomplicated urinary tract infection (UTI): the UTI Symptom Assessment questionnaire. British Association of Urological international Journal, 96 (3), 350-59.

- Cooper, D. L., Titler, M., Struble, L., \& Redman, R. (2017). A multifaceted, evidence-based program to reduce inappropriate antibiotic treatment of suspected urinary tract infections. Annals of Long-Term Care, 25 (2), 36-43.

- Elbeddini, A. (2018). Treatment Considerations in Urological Tract Infection (UTI). Journal of Pharmacy and Pharmacology Research, 2 (3), 93-5.

- Elokel, M. (2002). Prevalence of Alzheimer Dementia and other causes of Dementia in Egyptian elderly. Unpublished Master Thesis, Faculty of medicine. Ain Shams University.

- El-magrabi, N. Mahmoud s, \& Rashad, Abdelaziz S, Fahmy H. (2010). Assessment of elderly knowledge about urinary tract infection. In Assiut City. Journal Environment Research, 13 (1), 55-70.

- ElLawindi, M., Sayed, H., \& Shafei, E. (2014). Assessment of Urinary Tract Infections , Risk Factors and Knowledge among Attendees of Theodor Bilharz Research Institute , Giza , Egypt,1(1), 259.

- Flores-Mireles, A. L., Walker, J. N., Caparon, M., \& Hultgren, S. J. (2015). Urinary tract infections: Epidemiology, mechanisms of infection and treatment options. Nature Reviews Microbiology, 13 (5), 269-84.

- Folstin, J., Folstin, S., Hugh, M. (1975). Mini Mental State: Practical Method of Grading cognitive state of patients for The Clinician. Psychiatric Research, 12: 18995. 
- Fathy, H., Mohamed, G., Abd-Elsalam, N., \& Mossad, A. (2019). Self-Care Practices Regarding Prevention of Urinary Tract Infection among Secondary Nursing Students. Port Said Scientific Journal of Nursing, 6 (3), 195- 220.

- Fu, Z., Liska, D., Talen, D., Chang, M. (2017). Cranberry reduces the risk of urinary tract infection recurrence in otherwise healthy women: systemic Review and Meta-Analysis. Journal of Nutrition, 146 (12), 2282-8.

- Goldman, J. D., \& Julian, K. (2019). Urinary tract infections in solid organ transplant recipients: Guidelines from the American Society of Transplantation Infectious Diseases Community of Practice. Clinical Transplantation, 33 (9), 13507.

- Griebling, T. L. (2020). Asymptomatic Bacteriuria in Older Adults: The Most Fragile Women Are Prone to Long-Term Colonization. The Journal of Urology, 204 (1), 164-65.

- Gaurav, K., Mohan, T. S., Neeti, M., \& Siddique M.E, S. (2019). Prevalence of Urinary Tract Infections in Elderly Patients Attending A Tertiary Care Hospital. International Journal of Contemporary Medical Research, 6 (2), 16-19.

- Grealish, L., Pu, L., L., Jones, C., \& Moyle, W. (2020). The effectiveness of nurse-led interventions for preventing urinary tract infections in older adults in residential aged care facilities: A systematic review. Journal of clinical nursing, 29(9-10), 1432-44.

- Homma, Y., Gotoh, M., Yokoyama, O., Masumori, N., Kawauchi, A., Yamanishi, T., Ishizuka, O., Seki, N., Kamoto, T., Nagai, A., \& Ozono, S. (2011). JUA clinical guidelines for benign prostatic hyperplasia. International Journal of Urology, 18 (11), 10-3.

- Jump, R. L. P., Crnich, C. J., Mody, L., Bradley, S. F., Nicolle, L. E., \& Yoshikawa, T. T. (2018). Infectious Diseases in Older Adults of Long-Term Care Facilities: Update on Approach to Diagnosis and Management. Journal of the
American Geriatrics Society, 66 (4), 789803.

- Jena, R., Mandal, U., Kaur, G., Dash, S., Das, T. (2020). Knowledge and practice of staff nurses on prevention of UTI among patient with an indwelling catheter in selected hospital. European Journal of molecular and Clinical Medicine, 7 (11), 5070-80.

- Jonesa, J., Meyrickb, J., Bathb, O., Dunhamb, C. (2019). Effectiveness of behavioral interventions to reduce urinary tract infections and Escherichia coli bacteremia for older adults across all care settings: a systematic review. Journal of Hospital Infection, 102 (2), 200-18.

- Joseph, S. (2021). Educating Clinicians in a Nursing Facility to Proactively Manage urinary tract infection, Published doctoral Thesis, Walden University.

- Knight J. (2019). Effects of bed rest 4: renal, reproductive and immune systems. Nursing Times, 115 (3), 51-54.

- Kranz, J., Schmidt, S., Lebert, C., Schneidewind, L., Mandraka, F., Kunze, M., Helbig, S., Vahlensieck, W., Naber, K., Schmiemann, G., \& Wagenlehner, F. M. (2018). The 2017 Update of the German Clinical Guideline on Epidemiology, Diagnostics, Therapy, Prevention, and Management of Uncomplicated Urinary Tract Infections in Adult Patients. Part II: Therapy and Prevention. Urological Internationals Journal, 100 (3), 271-278.

- Khanal, N. (2014). Knowledge and practices among the care-takers of bedridden patients on prevention of urinary tract infection. Journal of Universal College of Medical Science, 2 (5), 24-9.

- Laura S. (2020). Prevalence of incomplete bladder emptying among elderly. Journal of Asian Gerontology and Geriatrics, 1 (2), 66-71.

- Lee, D. S., Lee, S., \& Choe, H. (2018). Community-Acquired Urinary Tract Infection by Escherichia coli in the Era of Antibiotic Resistance. Journal of Microbiology, 4 (2), 20-5. 
- Mody, L., \& Juthani-Mehta, M. (2014). Urinary tract infections in older women: A clinical review. JAMA-Journal of the American Medical Association, 311 (8), 844-54.

- Midthun, S., Bruce, W. (2015).Urinary tract infection in the elderly: A survey of physicians and nurses. Journal of Geriatric Nurse, 26 (4), 245-51.

- Matthews, S. J., \& Lancaster, J. W. (2011). Urinary tract infections in the elderly population. The American journal of geriatric pharmacotherapy, 9 (5), 286.

- Maclennon, W. (2010). Urinary tract infection in older patients. Journal of Clinical Geriatrics, 13: 119-27.

- Montoya A, Cassone M, Mody L. (2016). Infection in nursing homes, Epidemiology and prevention program. Clinical Geriatric Medicine, 32,585-607.

- Nicolle, L.E. (2018). Urinary Tract Infections in the Older Adult. Clinical Geriatric Medicine, 32 (3), 523-38.

- Rarrick, C., Leschorn, H., \& Hebbard, A. (2020). Impact of a urinary tract infection diagnostic and treatment algorithm for psychiatric inpatients with a communication barrier. Mental Health Clinician, 10 (2), 55-59.

- Statistical Records of the Main University Hospital, Alexandria, Egypt (2015).
- Statistical Records of Gamal Abd El Nasser Health Insurance Hospital, Alexandria, Egypt (2015).

- Statistical Records Damanhour National Medical Institute, El-Behaira, Egypt. (2019).

- Shallcross, L., Rockenschaub, P., Blackburn, R., Nazareth, I., Freemantle, N., \& Hayward, A. (2020). Antibiotic prescribing for lower UTI in elderly patients in primary care and risk of bloodstream infection: A cohort study using electronic health records in England. PLoS Medicine, 17 (9), 1-18.

- Sihra, N., Goodman, A., Zakri, R., Saha, i A., Malde, S. (2018). Non antibiotic prevention and management of recurrent urinary tract infection. Nature Urology 8(15), 750-76.

- Woodford H, George J. (2011). Diagnosis and management of urinary infection in older people. Journal of Geriatric medicine, 11 (1), 80-3.

- Wojszel, Z.B., Toczyńska-Silkiewicz, M. (2018). Urinary tract infections in a geriatric sub-acute ward-health correlates and atypical presentations. European Geriatric Medicine Journal 9, (4) 659-67. 